\title{
Analisis Kandungan Zat Pengawet Boraks Pada Sampel Jajanan Bakso di Desa Jatipurno Kabupaten Wonogiri
}

\author{
Winny Swastike, Shanti Emawati dan Ayu Intan Sari \\ Program Studi Peternakan Fakultas Pertanian \\ Universitas Sebelas Maret \\ Alamat respondensi:_winny.uns@gmail.com/081802501172
}

\begin{abstract}
ABSTRAK
Wonogiri merupakan daerah yang sangat terkenal sebagai daerah dimana masyarakatnya didominasi oleh pedagang bakso. Jenis bakso yang ditawarkan sangat beragam dari bakso yang disajikan bersama mie dalam bentuk kuah maupun bakso yang dijual satuan atau yang lebih dikenal dengan sebutan bakso bakar. Hal yang sangat dikhawatirkan adalah penggunaan boraks dalam bakso yang sering difungsikan sebagai pengenyal makanan. Keracunan boraks dapat terjadi melalui makanan, salah satunya adalah bakso sebagai salah satu jenis makanan yang sangat merakyat. Penelitian ini bertujuan untuk menganalisis kandungan boraks pada makanan khususnya jajanan bakso di Desa Jatipurno, Kabupaten Wonogiri. Jenis penelitian yang digunakan adalah Deskriptif Laboratorik dengan pemeriksaan laboratorium secara kualitatif dengan metode nyala api dan kuantitatif dengan metode titrasi asam basa. Populasi adalah semua jajanan bakso yang di desa Jatipurno, Kabupaten Wonogiri. Sampel diambil secara purposive sampling dari setiap penjual bakso. Hasil percobaan identifikasi senyawa boraks pada sampel bakso dengan metode nyala api, diketahui bahwa dari 50 sampel bakso yang diuji tidak menghasilkan nyala hijau yang berarti tidak terdeteksi adanya kandungan boraks pada sampel. Dari hasil penelitian disimpulkan bahwa bakso yang dianalisis dengan metode nyala api membuktikan bahwa sampel yang beredar di Desa Jatipurno, Kabupaten Wonogiri tidak teridentifikasi adanya boraks dan bebas dari kandungan boraks. Tidak dapat dilakukan penelitian kuantitatif untuk mengetahui kadar boraks dari jajanan bakso karena pada penelitian secara kualitatif menghasilkan nilai yang negatif (tidak mengandung boraks).
\end{abstract}

Kata kunci : Bahan Tambahan Pangan, jajanan bakso, boraks.

\section{Analysis Content Of Borax On Meatballs Snack In Jatipurno Village Wonogiri}

\begin{abstract}
Wonogiri an area that is well known as an area where people are dominated by traders meatballs. Type meatballs offered vary from meatballs served with noodles in the form of soup or meatballs are sold singly or known as grilled meatballs. Things are very concerned about is the use of borax in meatballs often functioned as chewing of food. Borax poisoning can occur through food, one of which is meatballs as one type of food that is very familiar. This study aimed to analyze the content of borax in food, especially meatballs in Jatipurno village, Wonogiri. This type of research is descriptive laboratory with laboratory tests are qualitative and quantitative methods of flame with acid-base titration method. The population is all hawker meatballs in Jatipurno village, Wonogiri. Sample was taken by purposive sampling of each meatball sellers. The experimental results on samples compound identification borax meatballs with flame method, note that of the 50 samples tested meatballs did not produce a green flame which means not detected borax content in the samples. The final conclusion is that the meatballs were analyzed by flame proving that the sample was circulated in Jatipurno village, Wonogiri is not identified free of borax and borax content. Not to do quantitative research to determine levels of borax meatballs snacks for the qualitative research produces a negative value (does not contain borax).
\end{abstract}

Keywords: Food Additives, meatball snacks, borax 


\section{PENDAHULUAN}

Wonogiri merupakan salah satu daerah di Jawa Tengah yang sangat dikenal dengan makanan khas nya yaitu bakso. Hampir di seluruh kota di Indonesia tersebar penjual bakso wonogiri, baik yang sudah menasional seperti bakso lapangan tembak, bakso titoti ataupun kios bakso baik besar maupun kecil (Kompasiana, 2011). Bakso daging merupakan makanan yang sudah populer, dibuat dari daging giling dengan bahan tambahan utama tepung tapioka dan bumbu, berbentuk bulat dan setelah dimasak memiliki rasa kenyal sebagai ciri spesifiknya.

Salah satu upaya yang dilakukan oleh produsen untuk menghindari kerugian akibat kerusakan tekstur bakso antara lain berjamur, berlendir, sehingga menimbulkan bentuk, warna, rasa dan bau berubah salah satunya dengan penambahan pengawet. Hal tersebut dilakukan untuk mendapatkan masa simpan bakso menjadi lebih panjang dan tidak menutup kemungkinan menambahkan zat kimia boraks sebagai pengawet, karena boraks harganya murah dan boraks berfungsi sebagai pengenyal (Winarno F.G., 2004).

Penambahan Bahan Tambahan Pangan (BTP) yang tidak sesuai aturan Undang Undang No.7 Tahun 1996 tentang Pangan dan Peraturan Pemerintah Nomor 28 tahun 2004 tentang Keamanan, Mutu dan Gizi Pangan sangat merugikan konsumen, karena mengabaikan aspek keamanan pangan bagi konsumen. Oleh sebab itu, pemilihan makanan jajanan yang aman dan berkualitas perlu diperhatikan (Fadilah, 2006).

Kondisi makanan dan minuman yang tidak sehat sangat merugikan karena anakanak dapat terinfeksi atau sakit bahkan keracunan dengan gejala antara lain mual, sakit perut, muntah, diare bahkan dapat menyebabkan kejang dan akhirnya fatal bila tidak segera mendapatkan pertolongan. Penggunaan bahan tambahan pangan (BTP) yang memang jelas-jelas dilarang, seperti bahan pengawet yang melampaui ambang batas yang telah ditentukan (Surianti, 2008). Dalam kehidupan sehari-hari BTP sudah digunakan secara umum oleh masyarakat termasuk dalam pembuatan makanan jajanan. Namun dalam prakteknya masih banyak produsen makanan yang menggunakan bahan tambahan yang berlebih sehingga dapat menjadi racun dan berbahaya bagi kesehatan yang sebenarnya tidak boleh digunakan dalam makanan, baik mengenai sifat-sifat keamanan Bahan Tambahan Pangan (BTP) (Fadilah, 2006).

Sejak lama, boraks disalah gunakan oleh produsen nakal untuk pembuatan kerupuk beras, mie, lontong (sebagai pengeras), ketupat (sebagai pengeras), bakso (sebagai pengenyal dan pengawet), kecap (sebagai pengawet), bahkan pembuatan bubur ayam (sebagai pengental dan pengawet). Padahal fungsi boraks yang sebenarnya adalah digunakan dalam dunia industri non pangan sebagai bahan solder, bahan pembersih, pengawet kayu, antiseptik dan pengontrol kecoa (Suhanda, 2012). Sering mengkonsumsi makanan berboraks akan menyebabkan gangguan otak, hati, lemak dan ginjal. Dalam jumlah banyak, boraks menyebabkan demam, anuria (tidak terbentuknya urin), koma, merangsang sistem saraf pusat, menimbulkan depresi, apatis, sianosis, tekanan darah turun, kerusakan ginjal, pingsan bahkan kematian (Nasution, 2009).

Keracunan boraks dapat terjadi melalui makanan, salah satunya adalah bakso sebagai jajanan anak-anak sekolah dasar. Ketertarikan anak-anak sekolah dasar membeli bakso dikarenakan harganya yang murah dan rasanya yang enak, sehingga anak-anak sekolah dasar menyukai makanan ini. Meskipun bakso sangat memasyarakat, ternyata pengetahuan masyarakat mengenai bakso yang aman dan baik untuk dikonsumsi masih kurang. Buktinya, bakso yang mengandung boraks masih banyak beredar dan tetap dikonsumsi. Menurut Damiyati (2007), formalin dapat memperpanjang daya awet bakso, sedangkan boraks dapat mengeyalkan bakso. Tetapi formalin dan boraks sangat 
membahayakan kesehatan (Sudarwati, 2007).

Fungsi bakso sebagai makanan merakyat menyebabkan bakso banyak diminati tanpa melihat kualitas makanan seringkali menjadi kekhawatiran masyarakat. Karena masih maraknya penggunaan boraks pada bakso, maka penelitian ini dianggap perlu dilakukan agar bisa memberikan rasa aman untuk para pengkonsumsi bakso. Penelitian ini bertujuan menganalisis kandungan zat pengawet boraks pada makanan jajanan bakso di Desa Jatipurno, Kabupaten Wonogiri tahun 2013.

\section{BAHAN DAN METODE}

Penelitian ini dilaksanakan selama bulan Oktober 2013. Lokasi penelitian bertempat di Desa Jatipurno, Kabupaten Wonogiri dan untuk analisis kadar boraks dilakukan di Laboratorium Balai Kesehatan Masyarakat dan Veteriner (BaPelKesMaVet) Boyolali. Jenis penelitian yang digunakan adalah Deskriptif Laboratorik dengan pemeriksaan laboratorium secara kualitatif dengan metode nyala api dan kuantitatif dengan metode titrasi asam basa. Populasi adalah semua jajanan bakso yang dijual di Desa Jatipurno, Kabupaten Wonogiri. Data yang dikumpulkan pada penelitian ini merupakan data primer, yaitu data yang diperoleh peneliti dari hasil wawancara dengan menggunakan pengambilan sampel langsung pada penjual bakso dan observasi langsung tentang pengetahuan, sikap dan tindakan penjual jajanan bakso. Data hasil penelitian berupa kadar boraks yang terdapat pada jajanan bakso akan dianalisis secara deskriptif. Penyajian data yang telah dianalisis disajikan dalam bentuk, grafik dan narasi untuk membahas hasil penelitian.

\section{HASIL DAN PEMBAHASAN}

\section{Hasil}

Analisis boraks pada 50 sampel yang dijual oleh penjual bakso di Desa Jatipurno, Kabupaten Wonogiri dengan menggunakan metode uji nyala direaksikan dengan pereaksi asam sulfat pekat dan methanol tidak menghasilkan nyala hijau yang berarti tidak terdeteksi boraks (Tabel 1). Pembuat makanan jajanan bakso yang dijual di Desa Jatipurno, Kabupaten Wonogiri yang memiliki karakteristik umur 38-50 tahun, semuanya berjenis kelamin laki-laki, penjual memiliki pendidikan tamatan SD sd SMA, lama usaha yang dijalani sekitar 3-5 tahun dan jumlah tenaga yang dimiliki penjual bakso 3 atau 5 orang (Tabel 2). Mengenai pengetahuan tentang sifat-sifat dan bahaya boraks penjual terhadap jajanan bakso di Desa Jatipurno, Kabupaten Wonogiri adalah cukup (Tabel 3). Dan untuk sikap penjual terhadap penggunaan boraks pada pembuatan jajanan bakso di Desa Jatipurno, Kabupaten Wonogiri yaitu positif (Tabel 4).

Tabel 1. Hasil Uji Boraks pada Sampel Bakso di Desa Jatipurno Kabupaten Wonogiri

\begin{tabular}{cccccc}
\hline Nomor Sampel & $\begin{array}{c}\text { Hasil Uji } \\
\text { Boraks }\end{array}$ & Nomor Sampel & $\begin{array}{c}\text { Hasil Uji } \\
\text { Boraks }\end{array}$ & Nomor Sampel & $\begin{array}{c}\text { Hasil Uji } \\
\text { Boraks }\end{array}$ \\
\hline A1 & - & A21 & - & A41 & - \\
A2 & - & A22 & - & A42 & - \\
A3 & - & A23 & - & A43 & - \\
A4 & - & A24 & - & A44 & - \\
A5 & - & A25 & - & A45 & - \\
A6 & - & A26 & - & A46 & - \\
A7 & - & A27 & - & A47 & -
\end{tabular}




\begin{tabular}{llllll} 
A8 & - & A28 & - & A48 & - \\
A9 & - & A29 & - & A49 & - \\
A10 & - & A30 & - & A50 & - \\
A11 & - & A31 & - & & \\
A12 & - & A32 & - & \\
A13 & - & A33 & - & \\
A14 & - & A34 & - & \\
A15 & - & A35 & - & \\
A16 & - & A36 & - & \\
A17 & - & A37 & - & \\
A18 & - & A33 & - & \\
A19 & - & A39 & - & & \\
A20 & - & A40 & - & \\
\hline
\end{tabular}

Tabel 2. Karakteristik Penjual Bakso di Desa Jatipurno Kabupaten Wonogiri

\begin{tabular}{lll}
\hline No & Parameter & Jumlah reponden (orang) \\
\hline 1 & Umur & \\
& a. $25-30$ & 15 \\
& b. $31-40$ & 25 \\
& c. $41-50$ & 10 \\
2 & \\
Pendidikan terakhir & 5 \\
& a. SD & 30 \\
& b. SMP & 15 \\
c. SMA & \\
Lama Usaha & 8 \\
a. $<5$ tahun & 12 \\
b. $5-10$ tahun & 30 \\
c. $>10$ tahun & \\
Jumlah tenaga kerja & 25 \\
& a. $1-3$ & 15 \\
b. $3-5$ & 10 \\
c. $>5$ &
\end{tabular}

Sumber: Data pribadi

Tabel 3. Distribusi Penjual Berdasarkan Pengetahuan Tentang Sifat-sifat dan Bahaya Boraks Pada Jajanan Bakso di Desa Jatipurno Kabupaten Wonogiri

\begin{tabular}{lccc}
\hline \multicolumn{1}{c}{ Responden } & Skoring & Persen & Kategori Pengetahuan \\
\hline Kategori A & 11 & $73,3 \%$ & Cukup \\
Kategori B & 13 & $86,6 \%$ & Cukup \\
Kategori C & 13 & $86,6 \%$ & Cukup \\
\hline
\end{tabular}

Sumber: Data Primer, 2013 
Tabel 4. Distribusi Penjual Berdasarkan Sikap Terhadap Penggunaan Boraks Pada Pembuatan Jajanan Bakso di Desa Jatipurno, Kabupaten Wonogiri

\begin{tabular}{lccc}
\hline \multicolumn{1}{c}{ Responden } & Skoring & Persen & Kategori Sikap \\
\hline Penjual A & 4 & $80 \%$ & Positif \\
Penjual B & 5 & $100 \%$ & Positif \\
Penjual C & 3 & $60 \%$ & Positif \\
\hline
\end{tabular}

Sumber: Data primer, 2013

\section{Pembahasan}

Dapat diketahui bahwa semua sampel yang telah diuji di laboratorium dengan metode nyala api menghasilkan reaksi nyala api berwarna biru yang menunjukkan bahwa sampel tersebut tidak mengandung bahan pengawet berbahaya boraks. Apabila dengan metode nyala api menghasilkan nyala api yang berwarna hijau, ini menunjukkan bahwa sampel tersebut mengandung boraks. Hasil dari penelitian ini sejalan dengan hasil penelitian yang dilakukan oleh Triastusi dkk. (2013) yang menyatakan bahwa bahwa tahu yang dianalisis dengan metode uji nyala, uji warna kertas kurkuma, uji warna kertas tumerik dan Spektrofotometri UV-Vis membuktikan kelima sampel tahu yang di produksi yaitu, sampel A (Bahu), sampel B (Batukota I), sampel C (Batukota II), sampel D (Kleak) dan sampel E (Pakowa) yang beredar di Kota Manado tidak teridentifikasi adanya boraks dan bebas dari kandungan boraks.

Bila boraks diberikan pada bakso dan lontong akan membuat bakso/lontong tersebut sangat kenyal dan tahan lama, sedangkan pada kerupuk yang mengandung boraks jika digoreng akan mengembang dan empuk serta memiliki tekstur yang bagus dan renyah. Parahnya, makanan yang telah diberi boraks dengan yang tidak atau masih alami, sulit untuk dibedakan jika hanya dengan panca indera, namun harus dilakukan uji khusus boraks di laboratorium.

Meskipun bukan pengawet makanan, boraks sering pula digunakan sebagai pengawet makanan. Selain sebagai pengawet, bahan ini berfungsi pula mengenyalkan makanan. Makanan yang sering ditambahkan boraks diantaranya adalah bakso, lontong, mie, kerupuk dan berbagai makanan tradisional seperti "lempeng" dan "alen-alen". Di masyarakat daerah tertentu boraks juga dikenal dengan sebutan garam bleng. Bleng atau pijer dan sering digunakan untuk mengawetkan nasi untuk dibuat makanan yang sering disebut legendar atau gendar (Yuliarti, 2007). Hal tersebut diperkuat dengan hasil penelitian Silalahi dkk. yang menunjukan bahwa $80 \%$ dari sampel bakso yang diperiksa ternyata mengandung boraks dan kadar boraks yang ditemukan berkisar antara 0,08-0,29\% dari berbagai lokasi yang diteliti, hasil tersebut sejalan dengan hasil penelitian yang dilakukan Sugiyatmi (2006) yang menunjukkan bahwa beberapa jenis makanan jajanan tradisional yang dijual di pasar-pasar Kota Semarang, terutama gendar, tercemar bahan toksik boraks.

Bila boraks diberikan pada bakso dan lontong akan membuat bakso/lontong tersebut sangat kenyal dan tahan lama, sedangkan pada kerupuk yang mengandung boraks jika digoreng akan mengembang dan empuk serta memiliki tekstur yang bagus dan renyah. Parahnya, makanan yang telah diberi boraks dengan yang tidak atau masih alami, sulit untuk dibedakan jika hanya dengan panca indera, namun harus dilakukan uji khusus boraks di laboratorium (Riandini, 2008).

Sering mengkonsumsi makanan berboraks akan menyebabkan gangguan otak, hati, lemak dan ginjal. Dalam jumlah banyak, boraks menyebabkan demam, anuria (tidak terbentuknya urin), koma, merangsang sistem saraf pusat, menimbulkan depresi, apatis, sianosis, tekanan darah turun, kerusakan ginjal, 
pingsan bahkan kematian (Widyaningsih dan Murtini, 2006).

Dalam hal ini perilaku seorang penjual sangat mempengaruhi kualitas dari makanan yang akan mereka jual. Perilaku pada dasarnya berorientasi pada tujuan. Dengan perkataan lain, perilaku kita pada umumnya dimotivasi oleh suatu keinginan untuk mencapai tujuan tertentu. Tujuan spesifik tersebut tidak selalu diketahui secara sadar oleh individu yang bersangkutan (Winardi, 2004). Skinner (1938) dalam Winardi (2004) seorang ahli psikologi merumuskan bahwa perilaku merupakan respons atau reaksi seseorang terhadap stimulus (rangsangan dari luar), oleh karena perilaku itu terjadi melalui proses adanya stimulus terhadap organisme dan kemudian organisme tersebut merespons.

Menurut teori Lawrance Green dkk. (1980) menyatakan bahwa perilaku manusia dipengaruhi oleh dua faktor pokok, yaitu faktor perilaku (behavior causes) dan faktor diluar perilaku (non behaviour causes). Selanjutnya perilaku itu sendiri ditentukan atau terbentuk dari 3 faktor. Yang pertama yaitu faktor predisposisi (predisposing factors), yang mencakup pengetahuan, sikap dan sebagainya. Kedua, faktor pemungkin (enabling factor), yang mencakup lingkungan fisik, tersedia atau tidak tersedianya fasilitasfasilitas atau sarana-sarana keselamatan kerja, misalnya ketersedianya APD, pelatihan dan sebagainya. Dan terakhir adalah faktor penguat (reinforcement factor), faktor-faktor ini meliputi undangundang, peraturan-peraturan, pengawasan dan sebagainya.

Pengetahuan merupakan hasil dari tahu, dan ini terjadi setelah orang melakukan penginderaan terhadap objek tertentu. Penginderaan terjadi melalui pencaindera manusia, yakni indera penglihatan, pendengaran, penciuman, rasa dan raba. Sebagian besar pengetahuan manusia diperoleh melalui mata dan telinga (Notoatmojo, 2003).

Berdasarkan hasil wawancara diketahui bahwa tingkat pengetahuan penjual tentang sifat-sifat dan bahaya boraks tergolong baik. Karena semua penjual jajanan bakso dapat menjawab pertanyaan dari kuesioner yang diberikan dengan benar. Sehingga, apabila pengetahuan seseorang baik, maka perilaku yang mereka timbulkan akan baik pula sesuai dengan pengetahuan yang telah mereka dapatkan selama ini. Hal ini sejalan dengan teori yang dikemukakan oleh Lawrance Green dkk. (1980) yang menyatakan perilaku itu sendiri ditentukan atau terbentuk dari dari beberapa faktor, salah satunya adalah faktor predisposisi (predisposing factors), yang mencakup pengetahuan, sikap dan sebagainya.

Berdasarkan karakteristik penjual pada data pendidikannya menunjukkan bahwa penjual jajanan bakso yang dijual di Desa Jatipurno, Kabupaten Wonogiri memiliki pendidikan rendah. Mereka hanya menempuh jenjang pendidikan sampai SMA bahkan dua diantara keseluruhan penjual hanya mampu menempuh jenjang pendidikan sampai SMP. Karena pendidikannya rendah maka pengetahuan, sikap dan prakteknya umumnya terbatas pada pengalaman dan kebiasaan yang dilakukan sehari-hari yang diperoleh secara turun-menurun. Namun seiring perkembangan teknologi informasi, pengetahuan tetang bahaya boraks tidak harus didapatkan melalui pendidikan formal. Para penjual mengaku mendapatkan informasi tentang bahaya boraks melalui media elekktronik saja sehingga mereka memahami resiko yang mereka dapatkan dan berikan ketika menggunakan boraks. Hal ini membuktikan bahwa walaupun mereka tidak memiliki tingkat pendidikan yang tinggi, tetapi mereka memiliki pengetahuan yang cukup baik mengenai boraks. Hasil dari penelitian ini sejalan dengan hasil penelitian yang dilakukan oleh Sugiyatmi (2006) yang menyatakan bahwa bahwa terdapat hubungan yang signifikan antara tingkat pengetahuan pembuat makanan jajanan mengenai bahaya boraks dengan sikapnya terhadap 
pengetahuan boraks dalam pembuatan makanan jajanan tradisional.

Sikap adalah determinan perilaku, karena mereka berkaitan dengan persepsi, kepribadian dan motivasi. Sebuah sikap merupakan suatu keadaan sikap mental, yang dipelajari dan diorganisasi menurut pengalaman dan yang menyebabkan timbulnya pengaruh khusus atas reaksi seseorang terhadap orang-orang, objekobjek dan situasi-situasi dengan siapa ia berhubungan (Winardi, 2004).

Berdasarkan hasil wawancara yang telah dilakukan dapat diketahui bahwa semua penjual jajanan bakso memiliki sikap yang positif untuk tidak menggunakan boraks dalam proses pembuatan makanan terutama bakso. Menurut Zimbardo dan Ebbesen, sikap adalah suatu predisposisi (keadaan mudah terpengaruh) terhadap seseorang, ide atau obyek yang berisi komponen-komponen cognitive, affective dan behavior (Ahmadi, 1999). Sikap terdiri dari berbagai tingkatan, yang pertama adalah menerima (receiving), menerima diartikan bahwa subjek mau dan memperhatikan stimulus yang diberikan. Kedua, merespon (responding), memberikan jawaban apabila ditanya, mengerjakan dan menyelesaikan tugas yang diberikan adalah suatu indikasi dari sikap. Ketiga, menghargai (valuing), mengajak orang lain untuk mengerjakan atau mendiskusikan suatu masalah adalah suatu indikasi sikap tingkat tiga. Dan terakhir yaitu bertanggung jawab (responsible), bertanggung jawab atas segala suatu yang telah dipilihnya dengan segala risiko merupakan sikap yang memiliki tingkatan paling tinggi (Notoatmojo, 2003). Sehingga sikap itu sendiri bisa lahir karena berbagai tingkatantingkatan yang mereka terima dari lingkungan sekitarnya. Hasil dari penelitian ini sejalan dengan hasil penelitian yang dilakukan oleh Sugiyatmi (2006) yang menyatakan bahwa bahwa terdapat hubungan yang signifikan antara sikap pembuat makanan jajanan tradisional yang dijual di pasar-pasar Kota Semarang terhadap penggunaan boraks dalam pembuatan makanan jajanan.

Dari pengetahuan dan sikap yang ada seseorang akan melahirkan sebuah tindakan atau praktek untuk sesuatu hal yang mereka lakukan. Berdasarkan hasil wawancara sebelumnya yang menyatakan bahwa penjual di Desa Jatipurno, Kabupaten Wonogiri memiliki pengetahuan yang baik dan sikap yang positif para penjual, sehingga pada prakteknya semua penjual juga memiliki nilai praktek yang baik. Hal ini didukung dari hasil wawancara yang dilakukan langsung pada penjual yang mengatakan bahwa boraks itu merupakan zat yang beracun dan dapat merusak kesehatan apabila dikonsumsi sehingga tidak baik untuk ditambahkan dalam proses pembuatan bakso.

Berdasarkan pada hasil analisis dan uraian di atas maka dapat dikatakan bahwa semua penjual memiliki pengetahuan dan sikap yang baik. Tingkat pengetahuan dan sikap merupakan salah satu faktor penting agar tidak terjadi pencemaran bahan toksin boraks.

Tidak ditemukannya boraks pada bakso yang dijual di Desa Jatipurno, Kabupaten Wonogiri dapat juga disebabkan karena adanya BPOM yang secara intensif melakukan pemeriksaan makanan dan dibawa langsung ke laboratorium untuk diuji keamanannya, informasi tersebut langsung didapatkan dari Kepala Desa Jatipurno, Kabupaten Wonogiri dan para penjual bakso.

Bakso yang dijual di Desa Jatipurno, Kabupaten Wonogiri dapat bertahan lama karena dari segi komposisi bakso dan cara perlakuannya. Berdasarkan hasil wawancara langsung kepada penjual bakso, peneliti dapat mengetahui komposisi untuk pembuatan bakso. Pada bakso halus, penjual menggunakan bahan dasar daging sapi dicampur dengan tepung kanji dengan perbandingan 4:3. Untuk bakso kasar menggunakan bahan dasar daging sapi dan urat dicampur dengan tepung kanji dengan perbandingan 5:3, bawang putih $1 / 4 \mathrm{~kg}$, penyedap rasa $50 \mathrm{gr}$, 
garam dan es batu yang disesuaikan pada proses pembuatan.

Dalam segi perlakuan bakso yang dijual dapat bertahan lama karena bakso tersebut selalu dalam keadaan hangat pada saat penjualan dan sisa dari bakso yang tidak terjual disimpan di dalam kulkas. Dengan perlakuan tersebut para penjual berpendapat bahwa bakso tersebut dapat bertahan hingga 4 hari.

\section{KESIMPULAN DAN SARAN}

Bakso yang dianalisis dengan metode nyala api membuktikan bahwa keseluruhan sampel bakso yang yang beredar di Desa Jatipurno, Kabupaten Wonogiri tidak teridentifikasi adanya boraks dan bebas dari kandungan boraks. Tidak dapat dilakukan penelitian kuantitatif untuk mengetahui kadar boraks dari jajanan bakso di Desa Jatipurno, Kabupaten Wonogiri karena pada penelitian secara kualitatif menghasilkan nilai yang negatif (tidak mengandung boraks).

Disarankan untuk penelitian selanjutnya, diharapkan menggunakan lebih dari satu metode untuk mengidentifikasi kandungan boraks secara kualitatif agar hasil lebih akurat. Dan sebaiknya untuk uji laboratorium, dalam pengambilan sampel dilakukan sekurangkurangnya tiga kali dalam rentang waktu yang berbeda agar lebih menguatkan hasil uji laboratorium.

\section{DAFTAR PUSTAKA}

Ahmadi, Abu. 1999. Psikologi Sosial. Jakarta: Rineka Cipta.

BPOM Republik Indonesia. 2008. Kamanan Pangan Jajanan Anak Sekolah (PJAS) Serta Upaya Penanggulangannya. Info POM Vol. 9, No. 6, November 2008. Jakarta: Badan Pengawas Obat dan Makanan.

Fadilah. 2006. Identifikasi Kandungan Bahan Tambahan Makanan (BTM) Pada Makanan Jajanan Anak SDN Kompleks Kota Palopo Tahun 2006.
Skripsi. Makassar: Universitas Hasauddin.

Nasution, Anisyah. 2009. Analisa Kandungan Boraks Pada Lontong di Kelurahan Padang Bulan Kota Medan Tahun 2009. Skripsi. Medan: Universitas Sumatera Utara.

Notoatmojo, Soekidjo. 2003. Pendidikan dan Perilaku Kesehatan. Jakarta: Rineka Cipta.

Riandini, N. 2008. Bahan Kimia dalam Makanan dan Minuman. Bandung: Shakti Adiluhung.

Sudarwati, 2007. Pembuatan Bakso Daging Sapi Dengan Penambahan Kitosan. Skripsi. Medan: Universitas Sumatera Utara.

Sugiyatmi, Sri. 2006. Analisis FaktorFaktor Risiko Pencemaran Bahan Toksik Boraks Dan Pewarna Pada Makanan Jajanan Tradisional Yang dijual Di Pasar-Pasar Kota Semarang Tahun 2006. Tesis. Semarang: Universitas Diponegoro.

Surianti. 2008. Studi Mutu Minuman Jajanan Pada Anak Sekolah Di SD Islam Athirah Kota Makassar Tahun 2008. Skripsi. Makassar: Universitas Hasanuddin.

Suhanda, Rikky. 2012. Higiene Sanitasi Pengolahan dan Analisa Boraks pada Bubur Ayam yang Dijual di Kecamatan Medan Sunggal Tahun 2012. Skripsi. Medan: Universitas Sumatera Utara.

Triastusi, E. Fatimawali, Max Revolta John Runtuwene. 2013. Analisis Boraks Pada Tahu Yang Diproduksi Di Kota Medan. Farmasi, 2 (01), hal 69-74.

Widyaningsih, Tri D. dan Murtini, E.S. 2006. Alternatif Pengganti Formalin Pada Produk Pangan. Jakarta: Trubus Agrisarana.

Winardi, J. 2004. Manajemen Perilaku Organisasi. Jakarta: Prenada Media. Yuliarti, N. 2007. Awas Bahaya Di Balik Lezatnya Makanan. Yogyakarta: Andi. 
